\title{
Robust Backstepping Speed Controller of a Doubly Fed Induction Motor using State-Space Nonlinear Approach
}

\author{
DJAMILA CHERIFI \\ Department of Electrical Engineering \\ University of Dr.Tahar Moulay \\ P. O. B. 138, 20000 Ennasr, Saida \\ ALGERIA \\ d_cherifi@yahoo.fr
}

\author{
YAHIA MILOUD \\ Department of Electrical Engineering \\ University of Dr.Tahar Moulay \\ P. O. B. 138, 20000 Ennasr, Saida \\ ALGERIA \\ miloudyahiadz@yahoo.fr
}

\begin{abstract}
The aim of this paper is an efficien cy Backstopping speed controller with direct stator flux orientation of doubly fed induction m otor (DFIM) fed b y two PWM inverters with separate DC bus link, the Backstopping controller is designed based on the L yapunov stability theorem, by introducing the approach for decoupling the motor's currents in a $r$ otating (d-q) frame, based on the state space input-output decoupling method. The purpose is therefore to make the speed and the flux control resist to parameter variations, because the variation of param eters during motor operation degrades the $\mathrm{p}$ erformance of the controllers. The proposed approach is a nalysed by Simulink/Matlab environment. The simulation results show good perform ance and robustness.
\end{abstract}

Key-Words: - Doubly fed induction motor (DFIM), backstepping control, state-space nonlinear approach

Received: November 1, 2019. Revised: April 13, 2020. Accepted: April 27, 2020. Published: May 11, 2020.

\section{Introduction}

Due to its good performance, robustness and easy maintenance, simplicity of construction, low cost, reliability, the doubly fed induction $m$ achine (DFIM) can provide a very attractive solution especially for variable-speed applications such as wind turbine systems, marine propulsion and electric vehicles [1], [2], [3], [4]. The control of the doubly fed induction machine (DFIM) is challenging, since the dynamical system is multivariable, coupled, and highly nonlinear due to the coupling between the flux and the electromagnetic torque [5], [6], [7]. The theory of decoupling by state feedback consists in ensuring an input-output decoupling of a $\mathrm{m}$ ultivariable system by means of a state feedback. This technique is of great theoretical and practical im portance insofar as it seeks to break down a multivariable system into several monovariable subsystems with similar dynamics. This decoupling $\mathrm{m}$ ethod is of particular interest to DFIM. However, the performance is sensitive to the variations of $\mathrm{m}$ achine parameters, because the control laws using the PI ty pe controllers give good results in the case of linear systems with constant parameters, but for nonlinear systems, these conventional control laws can be insufficient because they are not robust especially when the requirements on the speed and other dynamic characteristics of the system are strict [8], [9]. In order to im prove the performance of the
DFIM control and make it insensitive to parameter variations, and disturbances, we proposes the Backstepping speed controller. Backstepping control is an efficient method for nonlinear system. In the backstepping procedure, the first step is to define a virtual control state and then it is forced to become a stabilizing function. Consequently, by appropriately designing the related control input on the basis of Lyapunov stability theory, the error variable can be stabilized. Based on the backstepping design principle, the overall controller design can be established [10], [11].

This paper is organized as follows: principle of field-oriented control by decoupling state space is given in section 2, with his application to the DFIM. The Backstepping speed controller is presented in section 3 . In section 4, results of simulation tests are reported. Finally, section 5 draws conclusions.

\section{Vector Control Strategy of DFIM by Decoupling State Space}

To independently control the electrom agnetic force and the flux of DFIM it is necessary to make a judicious choice of reference. For this, one places oneself in a reference fram e (d-q) linked to the rotating field with an orientation of the stator flux (the axis $\mathrm{d}$ aligned with the direction of the stator flux), as the following figure shows 


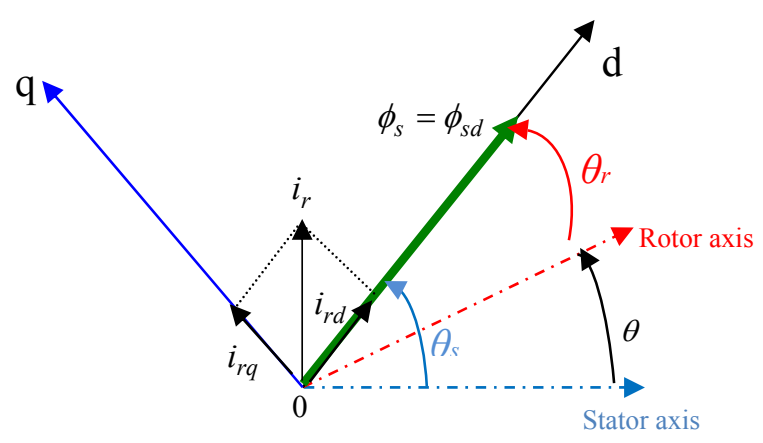

Figure 1: Stator field orientation on the d-axis

We obtain :

$$
\phi_{s d}=\phi_{s} \text { and } \phi_{s q}=0
$$

By imposing $\left(i_{\text {sd-ref }}=0\right)$ to ensure a unitary power factor working [12], [13].

Dynamic Model of DFIM:

$$
\left\{\begin{array}{l}
V_{s d}=R_{s} \cdot i_{s d}+\frac{d \phi_{s d}}{d t}-\left(\frac{d \theta_{s}}{d t}\right) \phi_{s q} \\
V_{s q}=R_{s} \cdot i_{s q}+\frac{d \phi_{s q}}{d t}-\left(\frac{d \theta_{s}}{d t}\right) \phi_{s d} \\
V_{r d}=R_{r} \cdot i_{r d}+\frac{d \phi_{r d}}{d t}-\left(\frac{d \theta_{r}}{d t}\right) \phi_{r q} \\
V_{r q}=R_{r} \cdot i_{r q}+\frac{d \phi_{r q}}{d t}-\left(\frac{d \theta_{r}}{d t}\right) \phi_{r d}
\end{array}\right.
$$

The fluxes are given by:

$$
\left\{\begin{array}{l}
\phi_{s d}=L_{s} i_{s d}+L_{m} i_{r d} \\
\phi_{s q}=L_{s} i_{s q}+L_{m} i_{r q} \\
\phi_{r d}=L_{r} i_{r d}+L_{m} i_{s d} \\
\phi_{r q}=L_{r} i_{r q}+L_{m} i_{s q}
\end{array}\right.
$$

We obtain :

$$
\left\{\begin{array}{l}
i_{s d}=\frac{1}{L_{s}}\left(\phi_{s d}-L_{m} \cdot i_{r d}\right) \\
i_{s q}=\frac{1}{L_{s}}\left(\phi_{s q}-L_{m} \cdot i_{r q}\right)
\end{array}\right.
$$

The electromagnetic torque is expressed by:

$$
T_{e m}=\frac{p L_{m}}{L_{s}}\left(\phi_{s q} i_{r d}-\phi_{s d} i_{r q}\right)
$$

Replacing equation (1) in (2) and (4) we find:

$$
T_{e m}=\frac{p L_{m}}{L_{s}}\left(-\phi_{s} i_{r q}\right)=-\frac{p L_{m}}{L_{s}} \phi_{s} i_{r q}
$$

and

$$
\left\{\begin{array}{l}
\phi_{s q}=0 \Rightarrow i_{s q}=-\frac{L_{m}}{L_{s}} i_{r q} \\
i_{s d}=0 \\
i_{r d}=\frac{\phi_{s}^{*}}{L_{m}}
\end{array}\right.
$$

$$
T_{e m}=p L_{m} i_{r d} i_{s q}
$$

\subsection{Currents Decoupling by State Space}

\subsubsection{Principle of the method}

Consider the following multivariable system:

$$
\left\{\begin{array}{l}
\dot{x}=A x+B u \\
y=C x
\end{array}\right.
$$

with $x \in \mathfrak{R}^{n}, y \in \mathfrak{R}^{m}, u \in \mathfrak{R}^{m}$

The objective is to determine a state space of the form:

$$
u=-K_{d} x+L_{d} v
$$

with $v \in \mathfrak{R}^{m}$

$v$ denotes the new input vector, which decouples the system, in a way that the output $y_{i}$ ( 1 to $\mathrm{m}$ ) depends only on the input $v$. The output $y_{i}$ is written:

$$
y_{i}=C_{i} x
$$

where $C_{i}$ is the ith row of the $\mathrm{m}$ atrix $C$. Let us derive $y_{i}$ a few tim es in order to bring up the command. We call characteristic index noted $\delta_{i}$, the num ber of derivation it takes in order to bring up the command. 
We then have successively for each output $i$ [14], [15]:

$$
\left\{\begin{array}{l}
\dot{y}_{i}=C_{i} \dot{x}=C_{i}(A x+B u)=C_{i} A x \\
\ddot{y}_{i}=C_{i} A \dot{x}=C_{i} A(A x+B u)=C_{i} A^{2} x \\
\ddot{y}_{i}^{(3)}=C_{i} A^{2} \dot{x}=C_{i} A^{2}(A x+B u)=C_{i} A^{3} x \\
\vdots \\
y_{i}^{\left(\delta_{i}\right)}=C_{i} A^{\delta_{i}} x=C_{i} A^{\delta_{i}-1} B u=C_{i} A x
\end{array}\right.
$$

Where $C_{i} A^{\delta_{i}} B \neq 0$ gives us the value of $\delta_{i}$

That we can still write in matrix form:

$$
\left[\begin{array}{c}
y_{1}^{\left(\delta_{1}\right)} \\
y_{2}^{\left(\delta_{2}\right)} \\
\vdots \\
y_{m}^{\left(\delta_{m}\right)}
\end{array}\right]=\left[\begin{array}{c}
C_{1} A^{\delta_{1}} \\
C_{2} A^{\delta_{2}} \\
\vdots \\
C_{m} A^{\delta_{m}}
\end{array}\right] x+\left[\begin{array}{c}
C_{1} A^{\delta_{1}-1} B \\
C_{2} A^{\delta_{2}-1} B \\
\vdots \\
C_{m} A^{\delta_{m}-1} B
\end{array}\right] u
$$

That is:

$$
y^{\prime}=A^{\prime} x+B^{\prime} u
$$

with $y \in \mathfrak{R}^{m}, \quad A^{\prime} \in \mathfrak{R}^{m \times m}$ and $B^{\prime} \in \mathfrak{R}^{m \times m}$

We seek a control law:

$$
u=-K_{d} x+L_{d} v \text { such as } y^{\prime}=v
$$

The looped system is written:

$$
\begin{aligned}
y^{\prime} & =A^{\prime} x+B^{\prime}\left(-K_{d} x+L_{d} v\right) \\
& =\left(A^{\prime}-B^{\prime} K_{d}\right) x+B^{\prime} L_{d} v
\end{aligned}
$$

To obtain $y^{\prime}=v$ we must have $B^{\prime} L_{d}=1$ and $A^{\prime}-B^{\prime} K_{d}=0$

If the matrix $B^{\prime}$ is invertible, the choice of :

$$
K_{d}=\left(B^{\prime}\right)^{-1} A^{\prime} \text { and } L_{d}=\left(B^{\prime}\right)^{-1}
$$

Gives: $y^{\prime}=v$

That is: $Y_{i}(s)=\frac{1}{s^{\delta_{i}+1}} V_{i}(s)$

\subsection{Application to the DFIM}

We search to exploit this method for decoupling the currents of the machine projected on a (d-q) rotating frame [16]. Starting from choosing a state vector equal to the output vector, formed of four currents of the machine. The input vector is formed of supply voltages. Then we obtain the following expression:

$$
\left\{\begin{array}{l}
\dot{x}=A x+B u \\
y=C x
\end{array}\right.
$$

with:

$x=\left[\begin{array}{llll}I_{s d} & I_{s q} & I_{r d} & I_{r q}\end{array}\right]^{T}$ the $\quad$ state vector $u=\left[\begin{array}{llll}V_{s d} & V_{s q} & V_{r d} & V_{r q}\end{array}\right]^{T}$ the input vector voltages

$A=\left[\begin{array}{cccc}-a_{1} & \omega+\omega_{s} & a_{3} & a_{5} \omega \\ -a \omega+\omega_{s} & -a_{1} & -a_{5} \omega & a_{3} \\ a_{4} & -a_{6} \omega & -a_{2} & -\frac{\omega}{\sigma}+\omega_{s} \\ a_{6} \omega & a_{4} & \frac{\omega}{\sigma}-\omega_{s} & -a_{2}\end{array}\right]$ $B=\left[\begin{array}{cccc}b_{1} & 0 & -b_{3} & 0 \\ 0 & b_{1} & 0 & -b_{3} \\ -b_{3} & 0 & b_{2} & 0 \\ 0 & -b_{3} & 0 & b_{2}\end{array}\right]$

$$
\begin{gathered}
C=\left[\begin{array}{llll}
1 & 0 & 0 & 0 \\
0 & 1 & 0 & 0 \\
0 & 0 & 1 & 0 \\
0 & 0 & 0 & 1
\end{array}\right]=I_{4} \\
a=\frac{1-\sigma}{\sigma} ; a_{1}=\frac{R_{s}}{\sigma L_{s}} ; a_{2}=\frac{R_{r}}{\sigma L_{r}} ; a_{3}=\frac{R_{r} L_{m}}{\sigma L_{s} L_{r}} ; \\
a_{4}=\frac{R_{s} L_{m}}{\sigma L_{s} L_{r}} ; a_{5}=\frac{L_{m}}{\sigma L_{s}} ; a_{6}=\frac{L_{m}}{\sigma L_{r}} ; b_{1}=\frac{1}{\sigma L_{s}} ;
\end{gathered}
$$


$b_{2}=\frac{1}{\sigma L_{r}} ; b_{3}=\frac{L_{m}}{\sigma L_{s} L_{r}} ; \sigma=1-\frac{L_{m}^{2}}{L_{s} L_{r}}$

The choice of $x=y$ makes the system completely controllable and observable. In apply ing the decoupling method on this system, it follows that:

$$
\forall i ; \delta_{i}=0 \text { and }\left\{\begin{array}{c}
L_{d}=B^{-1} \\
K_{d}=B^{-1} A
\end{array}\right.
$$

where: $L_{d}=\left[\begin{array}{cccc}L_{s} & 0 & L_{m} & 0 \\ 0 & L_{s} & 0 & L_{m} \\ v & 0 & L_{r} & 0 \\ 0 & L_{m} & 0 & L_{r}\end{array}\right]$

and:

$$
K_{d}=\left[\begin{array}{cccc}
-R_{s} & L_{s} \omega & 0 & L_{m} \omega_{s} \\
-L_{s} \omega_{s} & -R_{s} & -L_{m} \omega_{s} & 0 \\
0 & M_{s r}\left(\omega_{s}-\omega\right) & -R_{r} & L_{r}\left(\omega_{s}-\omega\right) \\
-L_{m}\left(\omega_{s}-\omega\right) & 0 & -L_{r}\left(\omega_{s}-\omega\right) & -R_{r}
\end{array}\right]
$$

$\dot{y}=u^{*}$, therefore: $\frac{Y i(s)}{u^{*}(s)}=\frac{1}{s}$

The four currents are decoupled and thus governed by the same transfer function in open loop

$$
G(s)=\frac{1}{s}
$$

\subsubsection{Design the Currents Control Loops}

The currents are decoupled, and then we can consider a state space correction with the method of placement of poles. The principal schem atic diagram of this correction is given by the figure 2 .

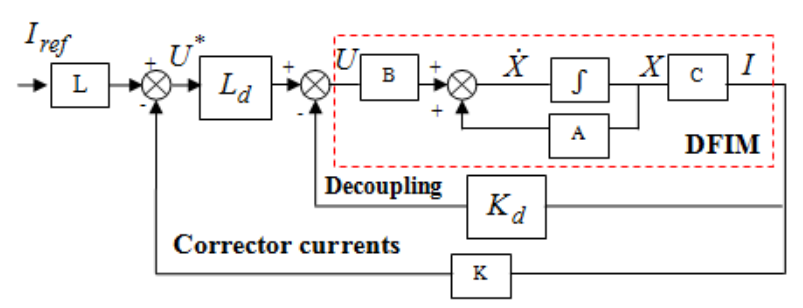

Figure 2: Current regulation by state space
To ensure the same response for the current loop, the next choice can be adopted.

$$
L=K=\left[\begin{array}{cccc}
K & 0 & 0 & 0 \\
0 & K & 0 & 0 \\
0 & 0 & K & 0 \\
0 & 0 & 0 & K
\end{array}\right]
$$

So the transfer function of each current closed loop will be of the form:

$$
H(s)=\frac{K}{K+S}
$$

\section{Backstepping Speed Controller}

The nonlinear systems control domain requires high performance algorithms to ensure a better level of stability and performance. The Backstepping control is part of the algorithms in this area. This technique, which was developed by Kanellakopoulos in 1990, offers a systematic method for producing controllers for nonlinear systems [17], [18], [19]. In this section, a robust backstepping controller design method based on the Lyapunov stability technique is developed for speed control of a doubly fed induction motor. The main control objective is to force the $\mathrm{m}$ otor speed to asy mptotically track a desired reference speed while simultaneously rejecting the external disturbances. Consequently , thes control thus helping it possible to operate the complete system in the best performances in the static and dynamic regimes.

The proposed design procedure includes the steps which are elaborately discussed as follows.

From this equation, it is not difficult to drive:

$$
\frac{d \Omega(t)}{d t}=\frac{1}{J}\left[T_{e m}(t)+T_{L}(t)+f \Omega(t)\right]
$$

where:

$$
\frac{d \Omega(t)}{d t}=a T_{e m}(t)+b T_{L}(t)+c \Omega(t)
$$

With: $\mathrm{a}, \mathrm{b}$ and $\mathrm{c}$ are constant param eters which are related to the motor parameters. 


$$
a=\frac{1}{J}, b=-\frac{1}{J}, c=\frac{f}{J}
$$

The first step of the Backstepping control is defined the speed track error:

$$
e(t)=\Omega_{r e f}(t)-\Omega(t)
$$

Then the derivative of speed track error can be represented as:

$$
\dot{e}(t)=\dot{\Omega}_{r e f}(t)-\dot{\Omega}(t)
$$

with:

$$
\dot{\Omega}(t)=a T_{e m}(t)+b T_{L}(t)+c \Omega(t)
$$

Then:

$$
\dot{e}=\dot{\Omega}_{r e f}(t)-a T_{e m}(t)-b T_{L}(t)-c \Omega(t)
$$

Subsequently we define the Lyapunov function of the form:

$$
V(t)=\frac{1}{2} e^{2}(t)
$$

Its derivative gives:

$$
\dot{V}(t)=e(t) \dot{e}(t)=e(t)\left[\dot{\Omega}_{r e f}(t)-a T_{e m}(t)-b T_{L}(t)-c \Omega(t)\right]
$$

In order to ensure the stability of the sy stem, it is necessary to make the derivative of the Ly apunov function

$V$ negative. For this, we defined a positive constant ' $K$ ' at derivative of equation

$$
\dot{V}(t)=-K e^{2}(t) \leq 0
$$

The expression of the electrom agnetic torque reference $T_{e m}^{*}$ is extracted from equation (25):

$$
T_{e m}^{*}(t)=\frac{1}{a}\left[\dot{\Omega}_{r e f}(t)-b \cdot T_{L}-c . \Omega(t)+K . e(t)\right]
$$

The block diagram of the proposed Backstepping speed controller system is shown in figure 3 .

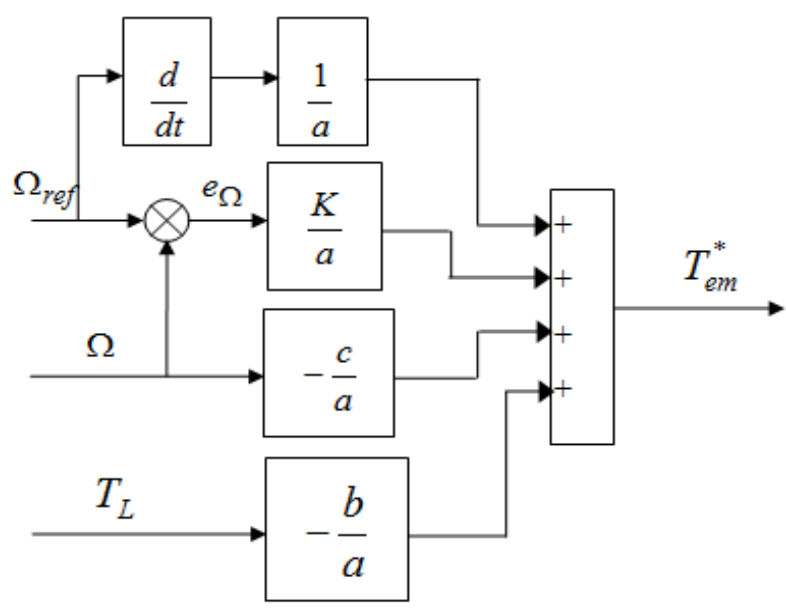

Figure 3: Block diagram of B ackstepping speed controller

\section{Results and Analysis}

To evaluate the performance of the proposed method, the model for the control law applied to the DFIM (Figure 4) has been im plemented in the Matlab / Simulink software.

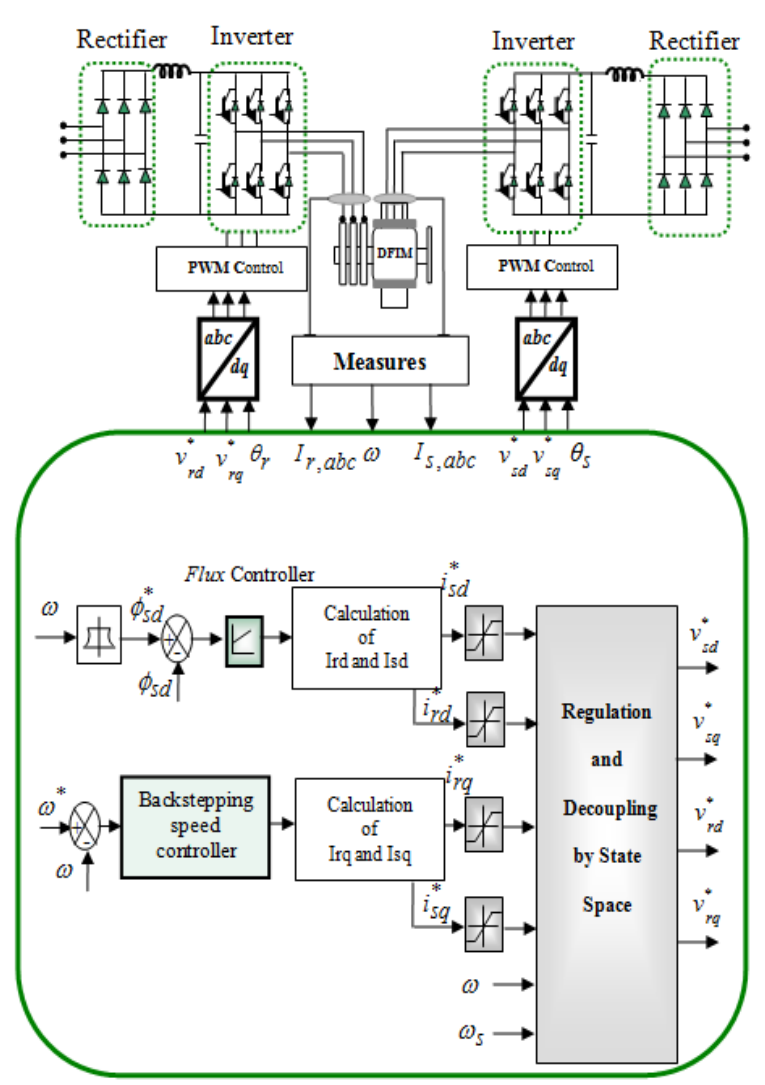

Figure 4: Block Diagram of robust Backstepping speed Controller of DFIM using a state space nonlinear approach 
Fig. 4 shows the different steps to turn out the control law of stator and rotor voltage. Accurate knowledge of the rotor speed and rotor flux are the keys factors in obtaining a high-performance and high-efficiency DFIM.

The system parameters of the DFIM tested in this study are given in Appendix.

\section{A. Constant Speed and Load Torque Application}

The first test (Figure. 5) concerns a no-load starting of the motor with a reference speed $\omega_{\text {ref }}=$ $250 \mathrm{rad} / \mathrm{s}$. and a nominal load disturbance torque (10N.m) is suddenly applied between $1 \mathrm{sec}$ and $2 \mathrm{sec}$.

From these results, it can be seen that the command using State-Space nonlinear approach has a better regulation (accuracy and stability) of the speed and even the stator flux, since the introduction of the charges has no influence on the evolution (stability) speed and also the flow, which shows the robustness of backstepping speed controller facing these disturbances compared to the conventional PI regulator.

This simulation results clearly show that, the decoupling between the electrom agnetic torque and the stator flux is very satisfactory.

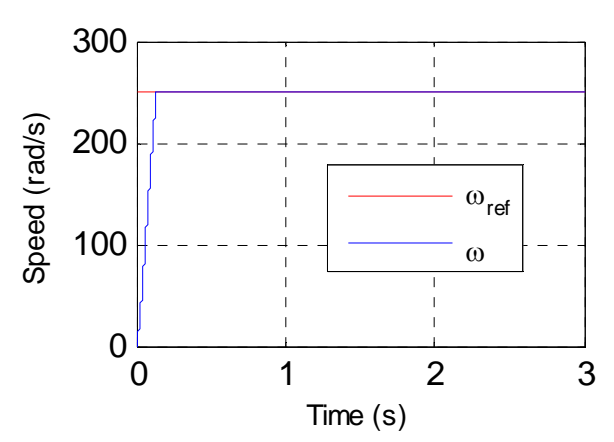

(a)

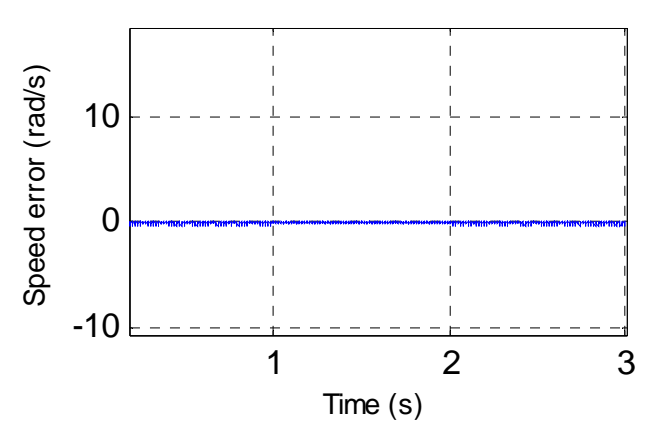

(b)

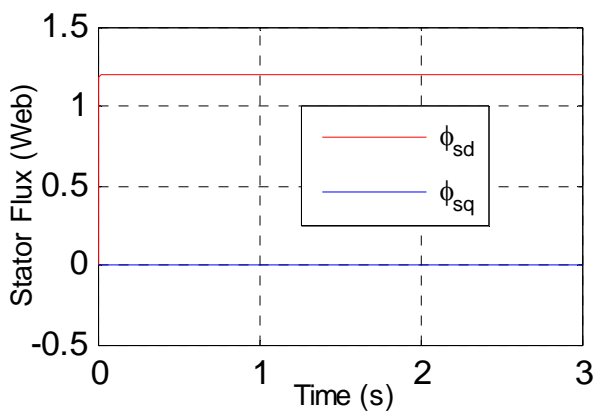

(c)

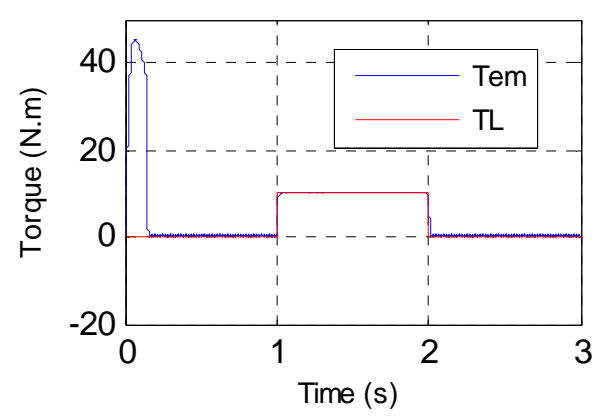

(d)

Figure 5: Sim ulation waveforms of proposed nonlinear control drives: a. Reference, Mesure Rotor speed, b. Zoom of Speed Error, c. Stator Flux, d. Electromagnetic torque waveform.

\section{B. Robustness test}

\section{Inverse Rotation Speed}

Figure 6 shows the evolution of the characteristics of the DFIM with speed control by backstepping controller, rotor and stator currents based on the input-output decoupling $\mathrm{m}$ ethod, followed by the inversion of the speed from 250 to $-250 \mathrm{rad} / \mathrm{s}$, with a load torque of $10 \mathrm{~N} . \mathrm{m}$ is suddenly applied between $1 \mathrm{sec}$ and $2 \mathrm{sec}$. As it's shown by figure a.6, the rotor speed tracks perfectly their reference with a static error equal to zero (Figure. 6. b).

This results express that the effect produced by the load torque variation is almost negligible for the system. also we notice decoupling between the electromagnetic torque and the stator flux is very satisfactory 


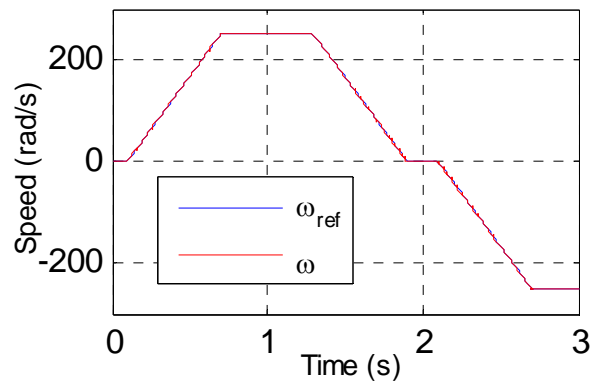

(a)

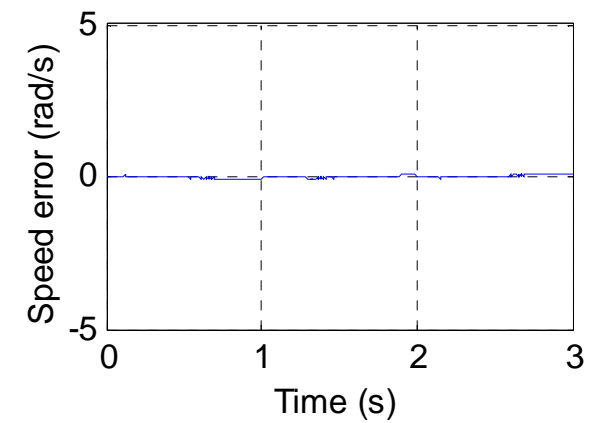

(b)

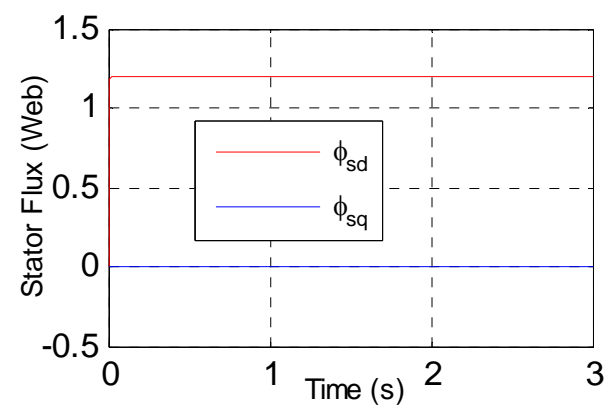

(c)

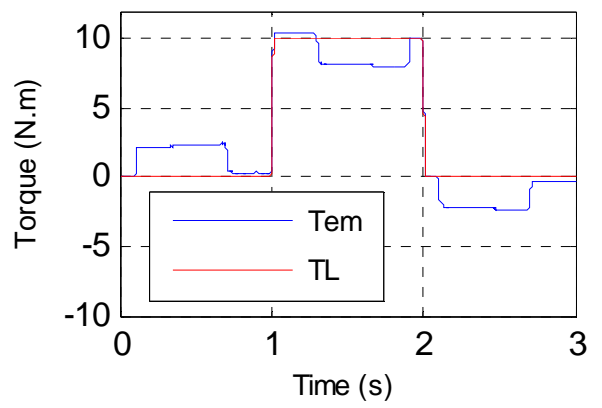

(d)

Figure 6: Sim ulation results of proposed nonlinear control drives with inverse rotation speed: a. Reference, Mesure Rotor speed, b. Speed Error, c. Stator Flux, d. Electromagnetic torque waveform.

\section{The rotor resistance variation test}

In order to study the influence of param etric variations on the behavior of the nonlinear control, we introduced a variation of $+50 \%$ of $\mathrm{R}_{\mathrm{r}}$ in the first test, we obtained the results as shown in the following figures:

According to the result of Figure. 7, we note that the increase in resistance did not affect the accuracy of a backstepping speed controller, we clearly see that the rotor speed perfectly follows its reference. An increase of the rotor resistance gives best performances.

The results of the speed control have shown that the control with backstepping speed controller ensures good performance even in the presence of parametric variations and external disturbances (load disturbance torque). As we see in this results, the increase in resistance did not affect the accuracy and orientation of the stator flux, which proves the robustness of the proposed controller. According to these results, we can say and in general, we obtained the same performance as the previous test with the nominal rotor resistance.

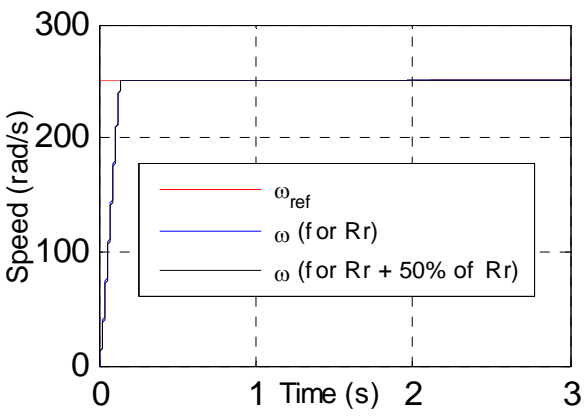

(a)

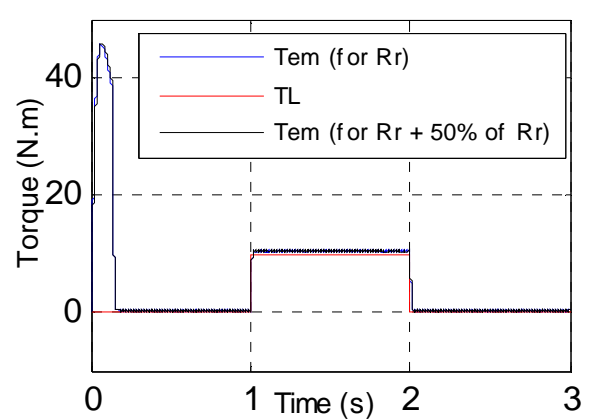

(b)

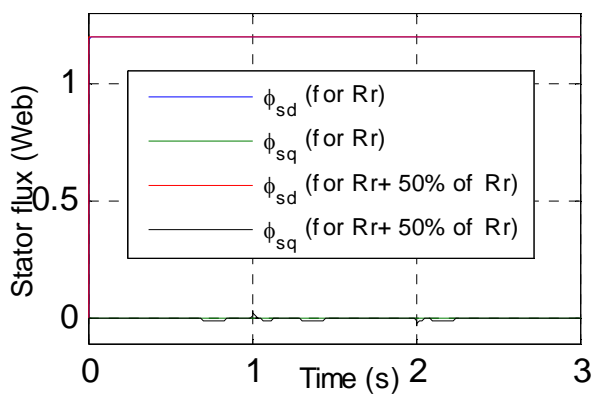

(c)

Figure 7: Si mulation results of proposed nonlinear control drives under a load change and with rotor resistance increased sharply by $50 \%$ from rated value 


\section{The stator resistance variation test}

For a nominal value of $\mathrm{R}_{\mathrm{r}}$, the stator resistance $\mathrm{R}_{\mathrm{s}}$ is increased by $+50 \%$ of its nominal value, we obtained the results as shown in the following figures: The obtained results (Figure.8) demonstrates that even if the stator resistance changes. This results shows also that using backstepping speed controller perform $\mathrm{s}$ a better control in terms of robustness

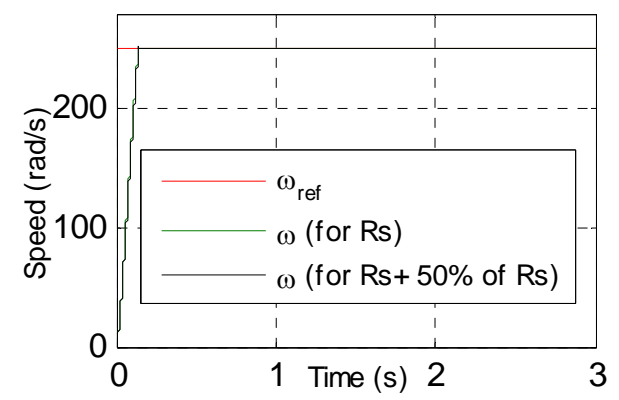

(a)

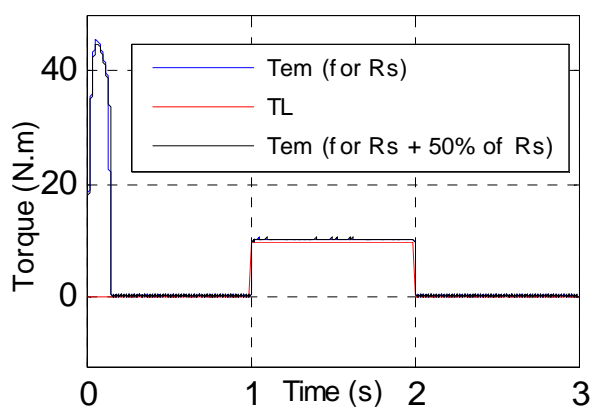

(b)

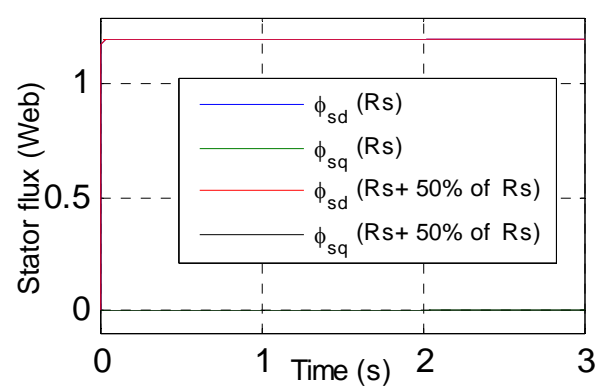

(c)

Figure 8: Simulation results of proposed nonlinear control drives under a load change and with stator resistance increased sharply by $50 \%$ from rated value

\section{Conclusion}

This paper deals with decoupling $m$ ethod of the currents for a vector control of a DFIM with stator flux orientation. This approach is based on the state space input-output decoupling, so we can obtain better decoupling for the currents between $\mathrm{d}$ and $\mathrm{q}$ axis. the backstepping speed controller was em ployed to solve different drawbacks of the conventional PI controllers and to obtain the better dynam ic performance from the DFIM in a speed control also $m$ ake it insensitive to param eter variations and disturbances.

Finally, we believe that the proposed solutions will improve the tra cking performance of the trajectory and disturbance rejection load Torque and parameter variations and also enhance stability through the robust look of the Backstepping speed controller.

\section{Appendix}

\section{DFIM motor parameters}

$\begin{array}{lcl}\text { Item } & \text { Symbol } & \text { Data } \\ \text { DFIM Power } & \mathrm{P}_{\mathrm{W}} & 1.5 \mathrm{Kw} \\ \text { Nominal speed } & \omega & 1450 \mathrm{rpm} \\ \text { Pole pairs number } & \mathrm{P} & 2 \\ \text { Stator resistance } & \mathrm{R}_{\mathrm{s}} & 1.68 \Omega \\ \text { Rotor resistance } & \mathrm{R}_{\mathrm{r}} & 1.75 \Omega \\ \text { Stator self inductance } & \mathrm{L}_{\mathrm{s}} & 295 \mathrm{mH} \\ \text { Rotor self inductance } & \mathrm{L}_{\mathrm{r}} & 104 \mathrm{mH} \\ \text { Mutual inductance } & \mathrm{L}_{\mathrm{m}} & 165 \mathrm{mH} \\ \text { Moment of inertia } & J & 0.01 \mathrm{~kg} \cdot \mathrm{m}^{2} \\ \text { friction coefficient } & F & 0.0027 \mathrm{~kg} \cdot \mathrm{m}^{2} / \mathrm{s} \\ \text { Nominal Frequency } & f & 50 \mathrm{~Hz}\end{array}$

References:

[1] R. Babouri, D. Aouzellag, K. Ghedam si, " Introduction of Dou bly Fed In duction Machine in an Electric Vehicle", Energy Procedia, 2013, pp. 1076 - 1084.

[2] Cherifi, Dj., Miloud, Y. "Speed sensorless control of a dou bly fed induction motor drives using MRAS estim ator", International Journal of Electrical Components and Energ y Conversion, Vol. 4, No. 1, pp. 1-12, 2018.

[3] Osama El-baksawi, Whale Opti mization Algorithm for Maxim um Power Point Tracker for Controllin $\mathrm{g}$ Induction Motor Driven by Photovoltaic System, WSEAS Transactions on Power Sy stems, pp. 70-78, Volume 14, 2019.

[4] Mahmoud M.S. Al-Suod, The Development of an Isolated Electric Power System Model to Determine the Voltage 
Dips during the In duction Motor Start, WSEAS Transactions on $\mathrm{P}$ ower Systems, pp. 2 23-233, Volume 14, 2019

[5] L. Yuan, H. Feng-You, Y. Zo ng-Bin, "Study on Sliding Mode Speed Control with Fuzzy Approch for Doubly -Fed Induction Motor", IEEE. International Conference on Conference, 2009.

[6] D. Ben Attous, Y. Bekaka, "Speed Control of a Doubly Fed Induction Motor us ing Fuzzy Logic Techniques", International Journal on Electrical Engineerin $g$ and Informatics, Vol 2, No 3 , 2010, pp. 179191.

[7] Souha Boukadida, Soufien Gdaim, Abdellatif Mtibaa, Hardware Implementation of a Neuro Fuzz y Based DTC-SVM of an In duction Motor on the FPGA, WSEAS Transactions on Power Systems, pp. 60-68, Volume 13, 2018

[8] N. Bounar, A. Boulkroune, F. Bo udjema, M. M'Saad, M. Farza, "Adaptive fuzzy vector control for a d oubly-fed induction motor", Neurocomputing, 2014, pp.1-14.

[9] V. M. Venkateswara Rao, G. Cha ndra Sekhar, Y. P. Obulesh, Artificial Neural Network and Adap tive Neuro Fuzzy Control of Direct Torqu e Control of Induction Motor for Speed and Torque Ripple Control, WSEAS Transactions on Power Systems, pp. 414 421, Volume 13, 2018

[10] B. Bossoufi, M. Ka rim, A. Lagrioui, M. Taoussi, "FPGA-based implementation nonlinear backstepping control of a PMSM drive", IJPEDS International Journal of Power Electronics and Drive Sy stem, March, Vol. 4, N o. 1, 2014, pp.12-23

[11] M. Karabacak, H I. Eskikurt, "Design, modelling and simulation of a new nonlinear and full adaptive backstep ping speed tracking controller for uncertain PMSM", Applied Mathematical Modelling, 2012, pp. 5199-5213.

[12] M. Abdellatif, M. Pietrzak-David, I. Slama-Belkhodja, "Sensitivity of the Currents Input-Output D ecoupling Vector Control of the DFIM versus Current Sensors Fault", 13th International Power Electronics and Motion Control C onference, EPEPEMC, 2008, pp 938-944.
[13] S. Khojet El Khil, I. SlamaBelkhodja, M. Pietrzak-David, B. Fornel, "Power Distribution Law in a Doubl y Fed Induction Machine", Special Issue of the Transactions of IMACS on Mathem atics and Computers in Sim ulation. Vol. 71, Edition Elsevier, 2006, pp.360-368.

[14] G. Salloum, R. Ghosn, M. PietrzakDavid, B. Fornel, "Robu stness of currents input-output decoupling in vector control of a doubly fed induction machine ", EPEPEMC, Riga Latvia, Septembre 2004.

[15] T. M. Chikouche, S. Hadjri, A. Mezouar, and T. Terras, "Robust Speed Control of a Doubl y Fed Induction Motor using State-Space Nonlinear Approach", Leonardo Journal of Sciences, Issue 22, pp. 103-122, 2013.

[16] P-E. Vidal, M-P. David, V. Bonnet, "Mixed control strategy of a doubl y fed induction machine", Springer-Vergal, 2007, pp.337-346

[17] M. El Azzaoui, H. Mah moudi, C. Ed-dahmani, " Backstep ping Control of a Doubly Fed Induction Gen erator Integrated to Wind Power Sy stem", 2nd International Conference on Electrical and Information Technologies ICEIT'2016.

[18] R. Trabelsi, A. Khedher, M F. Mimouni, F. M'sahli, " Backstepping Control for an Induction Motor Using an Adaptive Sliding R otor-Flux Observer", Electric Power Systems Research, 2012, pp. $1-15$.

[19] I. Benlaloui, S. Drid, L. ChrifiAlaoui, D. Benoudjit," Sensorless Speed Backstepping Control of Induction M otor Based on Sliding Mode Observer: Experimental Results ", 15th international conference on Sciences and Techniques of Automatic control \& computer engineering - STA'2014, Hammamet, Tunisia, December 21-23,2014, pp. 923-928. 